\title{
Las elecciones en Belice: del espejismo bipartidista a la realidad neocolonialista
}

Mónica Toussaint Ribot

$\mathrm{L}$ os partidos políticos surgen en Belice en el marco del proceso descolonizador iniciado después de la segunda guerra mundial, en el contexto de una continua amenaza a su soberanía $y$ en función de la lucha por la independencia, factores que van a conferir a los propios partidos políticos y al proceso electoral características francamente peculiares.

Además, la singularidad del caso beliceño tiene que ver también con tres elementos fundamentales. En primer lugar, su doble calidad de país centroamericano, por su ubicación geográfica, y de país caribeño dada su posición costera y sus lazos étnicos, históricos, sociales y culturales que lo vinculan claramente con el Caribe británico. ${ }^{1}$ En segundo término, su tan reciente independencia en 1981, a partir de la cual se han llevado a cabo dos elecciones: la de 1984, en la que obtiene la victoria el Partido Democrático Unido (UDP), y la de 1989, en la que triunfa el Partido Unido del Pueblo (PUP). Y, en tercero, la existencia de una amplia tradición participativa en la elección de sus autoridades y la constante lucha por la implantación del sufragio universal y del autogobierno como pasos previos a la obtención de su independencia.

'Cristina da Fonseca, "¿Quién le tiene miedo a Belice libre?", Nueva Sociedad, núm. 40, enerofebrero de 1979, Caracas, p. 64. 
Ahora bien, para una cabal comprensión del sistema político beliceño así como del reciente proceso electoral, es necesario hacer una revisión histórica del surgimiento de los partidos políticos, estrechamente vinculados en sus orígenes al movimiento sindical, así como de su posterior evolución.

\section{SINDICATOS Y PARTIDOS}

Las primeras organizaciones de trabajadores aparecen en Belice durante la segunda guerra mundial y tienen en sus inicios un carácter meramente reivindicativo de los derechos económicos de sus agremiados. Sin embargo, la evolución paulatina de sus demandas hacia planteamientos de corte político las hace convertirse en un elementocuestionador de la presencia británica en Belice, con todas las consecuencias que esta presencia había traído consigo y, por lo mismo, empiezan a actuar como factores que ponen en peligro la estabilidad institucional. Así, de las incipientes organizaciones gremiales surgen los primeros partidos políticos en Honduras Británica.

Rompiendo una larga tradición represiva contra los intentos de sindicalización, en 1941 se legaliza la actividad sindical en Belice y dos años después se promulga la Ordenanza de Patrones y Obreros. Ambas medidas dan pie para que un grupo de estibadores de la ciudad de Belice, dirigidos por Clifford Betson y Henry Middleton, constituyan el primer sindicato beliceño con el nombre de British Honduras Trade Union, a su vez antecedente del Sindicato General de Trabajadores (General Workers Union). Pero el movimiento obrero es todavía incipiente. Será cuando las autoridades tomen algunas medidas económicas, que deterioran las ya de por si precarias condiciones de vida de la mayoría de la población beliceña, que las organizaciones sindicales y políticas tomen un curso ascendente.

En septiembre de 1949 ocurre la devaluación de la libra esterlina con respecto al dólar estadunidense. Inicialmente, los beliceños ven de pronto incrementado su poder adquisitivo pero, casi de inmediato, la inversión británica en Belice se contrae ocasionando, como consecuencia, un agudo problema de desempleo. Además, dado que, a partir de la posguerra, Estados Unidos había sustituido a Inglaterra como principal abastecedor de productos manufacturados, los beliceños empiezan a contemplar la posibilidad de que una devaluación de su moneda traiga como resultado el aumento en el costo de todas las importaciones. Esto, aunado al creciente desempleo, resulta francamente catastrófico.

Dicha medida no tarda en llegar. El 31 de diciembre del mismo año, haciendo uso de los poderes de reserva, ${ }^{2}$ el gobernador, sir Roland Garvey, decreta la devaluaçión del dolar beliceño y su paridad con respecto a la libra esterlina. El gobierno argumenta, para justificar esta medida, que la devaluación es el paso necesario para promover el desarrollo económico del país; sin embargo, no se elabora un plan en este sentido. Únicamente, en un intento por reducir la gravedad de sus efectos, el gobernador anuncia la introducción de algunos subsidios y el control de precios.

\footnotetext{
${ }^{2}$ Los poderes de reserva son otorgados al gobernador en 1932 a cambio del préstamo que Inglaterra otorga a Belice para reparar los daños ocasionados por el huracán del año anterior y con el fin de reactivar la economía afectada por la cris is mundial de 1929.
} 


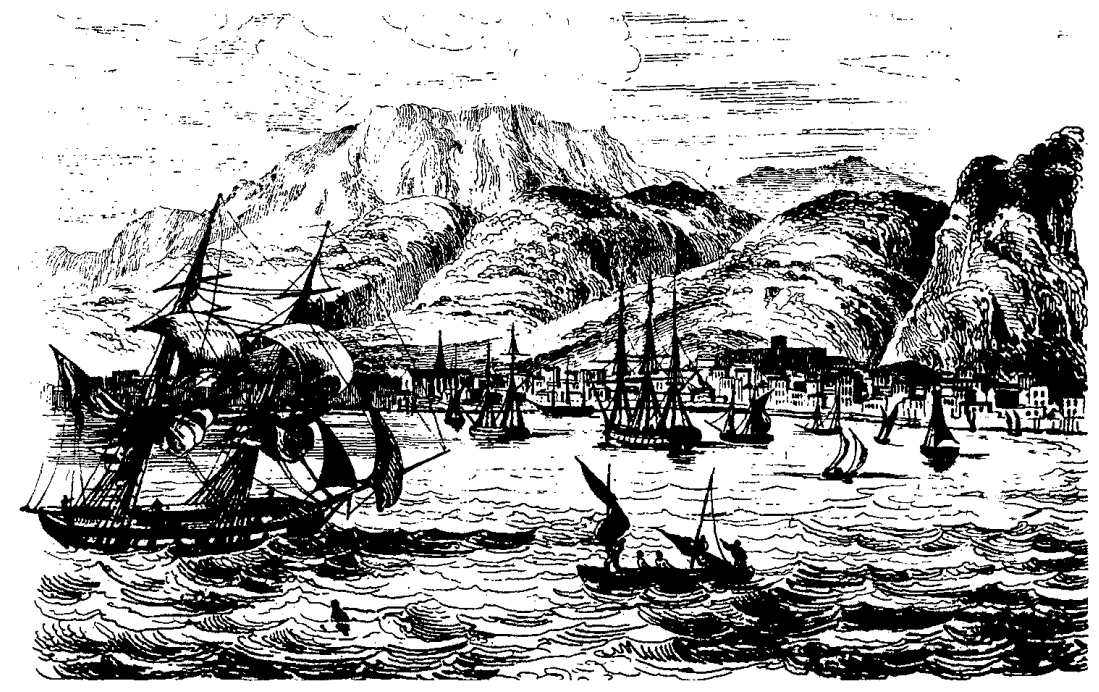

Con la idea de aprovechar esta coyuntura para organizar un movimiento que ponga fin a la dominación británica en Belice, los lideres John Smith, George Price y Nicholas Pollard -este último director del Sindicato de Oficinistas y Trabajadores de Comercios de la ciudad de Belice- constituyen el Comité del Pueblo (People's Committee) en la noche misma de la devaluación. El movimiento tieneun carácter plenamente anticolonial pero, a pesar de estarsustentado en el incipiente movimiento obrero beliceño, el Comité no esgrime los principios socialistas. De hecho, algunos de sus dirigentes están dispuestos a independizarse de la Gran Bretaña para entonces pasar a formar parte de Estados Unidos.

A partir de ese momento, las manifestaciones públicas en contra de las autoridades británicas invaden el escenario político, especialmente en los meses de. enero y febrero de 1950; como consecuencia se decreta el estado de emergencia y se establece la prohibición de di- chas manifestaciones. Noobstante, el movimiento continúa en ascenso y pronto se pone de manifiesto la necesidad de constituir un partido que logre unificar la actividad política en todo el país. Paralelamente, la relación entre el Sindicato General de Trabajadores y el Comité del Puebloes cada vez más estrecha, al grado de que el 28 de abril, en la convención anual de dicho sindicato, los dirigentes del Comité son electos integrantes de la mesa directiva sindical.

Al fin, en septiembre del mismo año, el Comité del Pueblo acuerda disolverse para dar lugar al nacimiento del Partido Unido del Pueblo (People's United Party, PUP), dirigido por John Smith, Leigh Richardson, George Price y Philip Goldson. El partido encuentra su mayor sustento en el movimiento de masas encabezado por el Sindicato General de Trabajadores lo cual hace posible que, en la primera elección del Consejo de la ciudad de Belice, en noviembre de 1950, resulten electos los candidatos del PUP; 
entre ellos se encuentran Henry Middleton, Philip Goldson y George Price, miembros de la mesa directiva del sindicato. Al igual que con el Comité del Pueblo, la alianza entre el sindicato y el partido se hace cada vez más orgánica por lo que en la nueva convención anual del sindicato celebrada en 1951, los líderes del PUP (Pollard, Price y Goldson), se convierten en miembros del consejo ejecutivo del sindicato ocupando los cargos de presidente, vicepresidente y secretario, respectivamente.

Al principio el PUP no encuentra oposición alguna. Sin embargo, algunos integrantes del Consejo Municipal de la ciudad de Belice que son a su vez miembros del PUP, se niegan, en agosto de 1951, a dar la autorización para que sea colgado un retrato del rey de Inglaterra en el ayuntamiento. Los miembros del Consejo Legislativo, proclives a la corona británica, proponen al gobernador que disuelva el Consejo Municipal y nombre otro que lo reemplace. Esta medida es acompañada por el encarcelamiento de Richardson y Goldson debido a sus artículos en el periódico opositor The Billboard. La mayoría de los miembros no oficiales del Consejo Municipal se afilian al Partido Nacional dirigido por Hebert Fuller, el cual, comparado con el PUP, tiene un nivel de organización sumamente endeble. Por ello, las autoridades deciden editar un periódico oficial llamado The British Honduras como un intento de restar influencia al PUP, pero no se obtienen los resultados esperados.

Poco a poco, el PUP va ganando cada vez más apoyo popular gracias al sentimiento nacionalista que se gesta en Belice. ${ }^{3}$ Signo de ello es que, en su primera

3 En sus orígenes, el pup se enmarca en una tendencia claramente nacionalista y democrática encabezada por George price, cuya meta funda- convención anual, el PUP acuerda cambiar el nombre de Honduras Británica por el de Belice y adoptar, en lugar de la bandera británica, una bandera azul y blanca con el emblema de los cortadores de madera. En 1954, año en que se conquista el sufragio universal adulto, sus candidatos a ia Asamblea Legislativa resultan electos con $65 \%$ de la votación total; y en 1955, con base en el nuevo sistema ministerial, algunos de sus dirigentes llegan a ocupar puestos dentro del gobierno, entre ellos Richardson, Goldson, McMillan y Price. De aquí que, debido a esta fuerte derrota en las elecciones, el Partido Nacional se retire de la vida política durante tres años.

En ese momento, uno de los objetivos del pup consiste en arribar a los cargos públicos con el fin de transformar al gobierno "desde adentro". Desde ahí se busca lograr también algunos beneficios para las masas trabajadoras, cuyas condiciones de vida continúan en franco deterioro a lo largo de la década de los cincuenta. Sin embargo, a pesar de las sucesivas huelgas de trabajadores de los aserraderos, de obras públicas y portuarios, las autoridades coloniales, en alianza con las compañías extranjeras, llevan adelante una política encaminada a debilitar al movimiento huelguístico y a obligar a los trabajadores a aceptar mejorías mínimas. Esta situación refuerza aún más la ideología anticolonial del PUP. ${ }^{4}$

mental es la independencia total del país y la salvaguarda territorial. En lo internacional, el pup se vincula con la Internacional Socialista y se inscribe en una posición tercermundista de lucha contra el colonialismo y el racismo, en pro de la paz y de un nuevo orderr económico, Cristina da Fonseca, $o p$. cit., p. 66 .

4Además, en su discurso, el pup propugna por una justa distribución de la riqueza y un nuevo orden social sin la explotación del hombre por el hombre. 
A pesar de la renuncia de John Smith en 195: debida a la actitud procentroamericana de Price, el PUP mantiene la cohesión interna hasta 1955, año en que empiezan a ser evidentes las diferencias ideológicas y políticas entre sus dirigentes. George Price se niega a participar en las instancias propias del gobierno colonial, mientras Richardson y Goldson empiezan a considerar ventajoso mantener e incrementar los vínculos económicos tanto con la Gran Bretaña como con sus colonias en Las Antillas. En agosto de 1956, Richardson y Goldson son obligados a renunciar a sus puestos en el gobierno y, en septiembre, son expulsados del partido, quedando como líder máximo George Price. Al salir del PUP, Richardson y Goldson forman un nuevo partido político: el Partido de la Independencia Hondureña (Honduran Independence Party), y mantienen el control del Sindicato General de Trabajadores.

El PuP vuelve a dividirse en 1958 al ser expulsado Pollard. Éste es depuesto tres años antes del cargo de secretario del Sindicato General de Trabajadores acusado de fraude y, al salir, constituye el Sindicato Demócrata Cristiano junto con Price. Después de abandonar el pup, Pollard funda el Partido Democrático de los Trabajadores Agrícolas (Democratic Agricultural Labour Party) que tiempo después cambia su nombre por el de Partido Demócrata Cristiano (PDC). Ese mismo año, el Partido Nacional (PN) ${ }^{5}$ y el Partido de la Independencia Hondureña (PIH) se fusionan para formar el Partido de la Independencia Nacional (PIN), dirigido por Hebert Fuller, J.L. Meighan, Jaime Staines y Philip Goldson. El PIN y el PuP tienen planteamientos ideológicos

sLa creación del Partido Nacional es promovida por el propio gobierno británico con el fin de constituir una instancia política en oposición al puP que frene el movimiento nacionalista. similares; no obstante, el PIN propone postergar la independencia hasta contar con una base económica y una fuerza armada capaces de garantizar la soberanía nacional. ${ }^{6}$

Igualmente, el movimiento sindical experimenta en este periodo un proceso de reagrupamiento de las fuerzas que lo integran hasta conformar dos tendencias fundamentales. La primera, el Congreso Nacional Sindical de Belice (National Trade Union Congress of Belize), se constituye en 1966 con la unión del Sindicato General de Trabajadores del Desarrollo de Belice, el Sindicato Nacional de Profesores de Belice, el Sindicato Cristiano del Sur y el Sindicato de Trabajadores Públicos. La segunda, la Federación Nacional de Sindicatos Cristianos, con un menor número de afiliados, agrupa al Sindicato de Trabajadores Cristianos, al Sindicato de Trabajadores del Sector Azucarero y al Sindicato de Trabajadores de Cayo. Al margen de ambas centrales obreras se encuentra también el Sindicato Independiente, de muy escasa importancia en la vida política beliceña.

Al inicio de la década de los setenta se incrementa la amenaza de una agresión guatemalteca a Belice, la cual unifica a las fuerzas de oposición. En 1974 éstas deciden formar una coalición y fundan entonces el Partido Democrático Unido (PDU), dirigido por Dean Lindo. Al mismo tiempo, acuerdan postergar la independencia hasta noreunir las condiciones de desarrollo y defensa que garanticen que,

\footnotetext{
${ }^{6}$ Por su parte, Price empieza a aceptar la idea de la descolonización paulatina, para lo cual el movimiento obrero se convierte en un elemento necesario sólo en la coyuntura electoral. Así, a partir de la década de los sesenta, Price concibe que la independencia no puede depender del apoyo popular, sinoque requiere, necesariamente, de la cooperación británica.
} 
el tránsito de colonia a país independiente, tenga la suficiente solidez para posibilitar su continuidad, y esperar además que Guatemala ceda a su reclamo. Después del fracaso electoral de 1979, Theodore Aranda se convierte en nuevo líder y permanece en el cargo hasta 1982, cuando es expulsado bajo la acusación de recibir dinero guatemalteco. Manuel Esquivel pasa entonces a ser el nuevo dirigente del partido. ${ }^{7}$

\section{DEL AUTOGOBIERNO A LA INDEPENDENCIA}

Podemos afirmar que en las tres décadas previas a la independencia, el PUP domina la escena política beliceña debido tanto al apoyo del movimiento sindical como a la debilidad de la oposición. Sin embargo, al comenzar los añossesenta el PUP adquiere una mayor fuerza política gracias a que, en 1963, se vota una constitución de transición a la independencia $\mathrm{y}, \mathrm{al}$ año siguiente, Belice accede al autogobierno. ${ }^{8}$

A partir de entonces, el pup tratará de conjugar dos elementos: poruna parte, la instauración de un programa de gobierno que procure elevar los niveles de vida de la población beliceña y promueva la integración nacional y, por otra, el desarrollo de la batalla internacional por la independencia en el terreno diplomático. El objetivo, lograr un sólido apoyo interno para así tener una fuerza real en el ámbito de la negociación diplomática.

\footnotetext{
7 Para todo el apartado, Mónica Toussaint, Belice: una bistoria breve, inédito; Pablo Álvarez Icaza, Belice: La crisis, el neocolonialismo y las relaciones con México, 1978-1986, PECA-CIDE, México, 1987, pp. 42-44 y Assad Shoman, Party politics in Belize 1950-1986, Cubola Productions, Belice, 1987, pp. 18-27.

${ }^{8}$ El Puf triunfa en las elecciones de 1964 y se mantiene en el poder hasta 1984.
}

Lo que se conoce en Belice como la Revolución Nueva, Pacífica y Constructiva impulsada por Price tiene cinco ejes fundamentales: 1) la educación; ; 2) la promoción deuna legislación laboral progresista; 3) reforma agraria y el desarrollo del movimiento cooperativo; 4) la reglamentación de las actividades del capital extranjero, y 5) la defensa de los recursos naturales.

No obstante, desde entonces, Price esgrime planteamientos de política económica basados, fundamentalmente, en la penetración del capital extranjero como punto de partida para el desarrollo económico en Belice. ${ }^{10}$ Esta política no genera, en los hechos, el bienestar social esperado. De aquí que el gobierno de Price a lo largo de dos décadas se sustente, sobre todo, en un estilo personal y paternalista de liderazgo, basado en alianzas y fidelidades familiares y personales. ${ }^{11}$

\section{DOS PALABRAS SOBRE EL SISTEMA POLITICO-ELECTORAL}

El gobierno de Belice funciona con base en los principios de la democracia parlamentaria, siguiendo el modelo británico. El poder ejecutivo esta compuesto por el primer ministro y su gabinete, mientras que el poder legislativo (Asamblea Nacional) esta formado por dos cámaras: la de Diputados, integrada por 28 miembros electos, y la de Senadores, conformada por ocho miembros desig-

\footnotetext{
${ }^{9}$ Como consecuencia del esfuerzo del pup se reduce drásticamente el analfabetismo.

${ }^{10}$ Entre 1975 y 1981 se establecen en Belice tres transnacionales norteamericanas de alimentos, Pablo Álvareż Icaza, op cit., p. 33.

${ }^{11}$ Para todo el punto Carlos Quenan, "Belice: causas y perspectivas de una independencia tardia", Nueva Sociedad, marzo-abril de 1982, Caracas, pp. 80-85 y Assad Shoman, op. cit, pp. 28-40.
} 
nados. La reina Isabel II es la jefa de Estado y está representada por un gobernador general, quien debe ser beliceño. El gobernador general, asesorado por el primer ministro, nombra a los ministros integrantes del gabinete. Igualmente, los senadores son nombrados por el gobernador, cinco con la asesoría del primer ministro, dossegún la opinión del líder de la oposición y uno por sugerencia del llamado Consejo Asesor de Belice. Naturalmente, el primer ministro es el líder del partido que obtiene la mayoría en las elecciones de diputados.

Las elecciones, que tienen lugar cada cinco años, funcionan con base en ciertas reglas mínimas, ya que no se cuenta con leyes elaboradas que regulen minuciosamente la actividad partidaria. Así, existen 28 divisiones electorales, en cada una delascuales, todo adulto puede ser candidato y, la persona con mayor número de votos, se convierte en miembro de la Cámara de Diputados. El votoes secreto, no obligatorio; tienen derecho a votar todos los ciudadanos mayores de 18 años y, desde 1978, existe un registro de votantes a los cuales se les otorga una credencial de elector. ${ }^{12}$

El objetivo de este modelo consiste en garantizar la continuidad de la influencia

${ }^{12}$ Fact Sbeet: Belize, A government Information Service Publication, Belize, 1989, pp. 2-3 y Assad Shoman, op. cit., pp. 52-57.

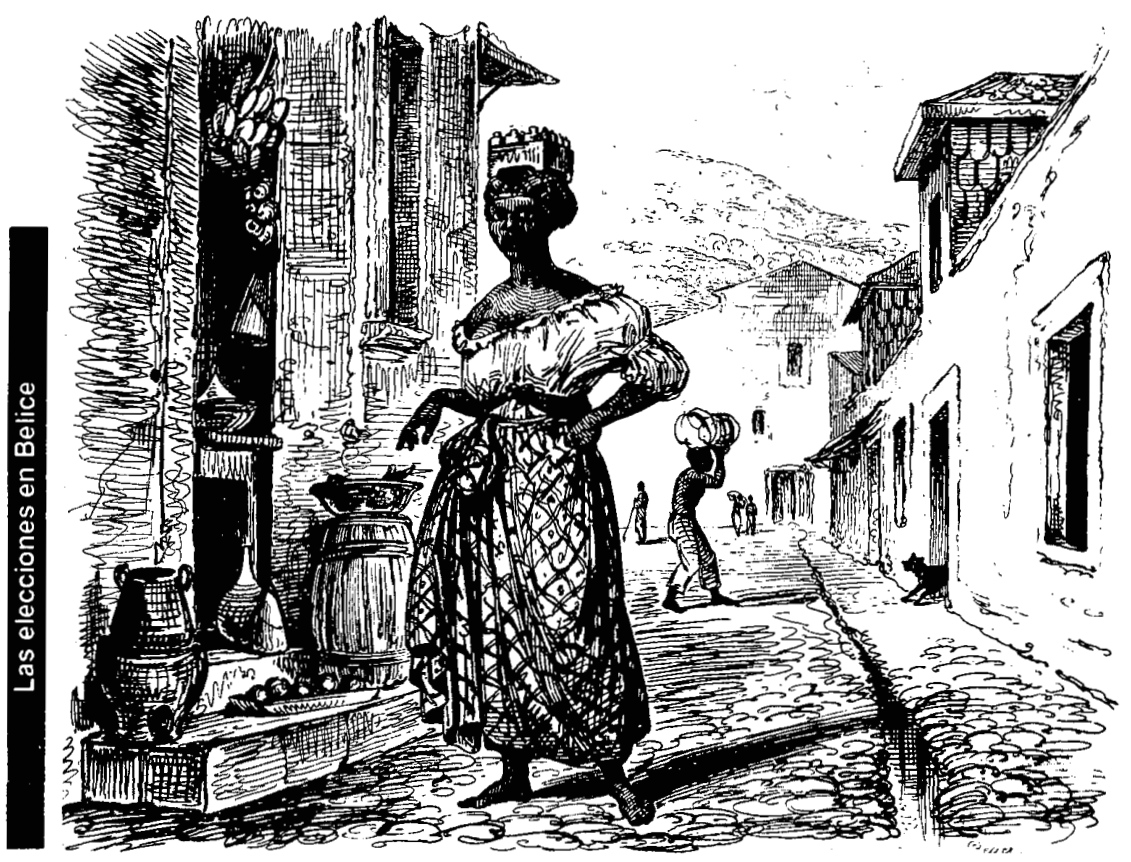


británica después de la independencia en 1981; sin embargo, cada vez .ılás, se ha convertido en un elemento de contradicción con la propia independencia y la soberanía de los beliceños.

\section{ELECCIONES Y ALTERNANCIA}

En las primeras elecciones de su vida independiente, en diciembre de 1984, el hasta entonces dominante Partido Unido del Pueblo es derrotado abrumadoramente por el opositor Partido Democrático Unido, el cual, aprovechando el paulatino desgaste que venía experimentando el PuP, logra conquistar 21 de los 28 escaños de la Cámara de Diputados. Realmente no se trata tanto de un triunfo del PDU, sino de un rechazo a Price y al PUP. En suma, la derrota del PUP se explica por el repudio de los beliceños a la administración con 30 años en el poder. ${ }^{13}$

De esta manera, el líder dela independencia beliceña, George Price, a los 65 años de edad, es desplazado del gobierno debido a varias causas: la corrupción e ineficiencia del PUP, el conflicto ideológico dentro del partido, ${ }^{14}$ el deterioro en la economía y en el nivel de vida del pueblo beliceño como consecuencia de la crisis económica y, por último, las acusaciones de la CiA por la simpatía del gobierno de Price hacia Cuba y Nicaragua. ${ }^{15}$

\footnotetext{
${ }^{13}$ De gran dramatismo resulta la derrota de Price en su propia adscripción electoral; su contendiente obtiene $60 \%$ de los votos y además, es la primera vez que el pup pierde las elecciones en la ciudad de Belice.

${ }^{14} \mathrm{El}$ ala izquierda forma el Movimiento para la Dirección Democrática que denuncia la corrupción y la antidemocracia en el partido gobernante, Pablo Álvarez Icaza, op. cit., pp. 45-46.

is Assad Shoman, miembro del gabinete de
}

El nuevo primer ministro, Manuel Esquivel, de 43 años y profesor de fisica educado en Estados Unidos, se plantea dos objetivos básicos: 1) una política en pro de la libre empresa, y 2) propiciar una decidida actitud favorable a los inversionistas privados extranjeros, fundamentalmente de Estados Unidos, Jamaica y México, países de los que Esquivel busca atraer capitales destinados al turismo, la energía y la agricultura.

Podemos hacer hoy un balance del gobierno de Esquivel en dos sentidos. El primero, en sentido social, durante el gobierno de Esquivel no se produce una mejoría con respecto al gobierno de Price, sino que se incrementa el deterioro económico de la población: el desempleo llega a $20 \%$, se incrementa el subempleo, aumenta el costo de la vida, crecen las cargas impositivas $y$, por si esto fuera poco, disminuye el gasto social. ${ }^{16} \mathrm{El}$ segundo se encuentra relacionado con el problema de la soberanía y podemos hablar de un saldo negativo. Esun hecho que la presencia de Estados Unidos en Belice se incrementa a lo largo de estos cinco años (1984-89) y muestra de ello son la constante ayuda de la AID, ${ }^{17}$ el considerable aumento del personal de la embajada norteamericana en Belice (de 7 a 47), la venta de tierras a empresas norteamericanas, ${ }^{18}$ la instalación en Pun-

Price, incluye también como causas de la derrota del pup la falta de credibilidad de su dirigencia y la baja moral de sus bases, Assad Shoman, op. cit., p. 5 .

${ }^{16}$ Noel Fursman, "Belice: balance de los dos primeros años de vida independiente", Foro Internacional, núm. 94, octubre-diciembre de 1983, México, pp. 131-154; Michael, Witter, "Belice: el desafio de la independencia", Nueva Sociedad, núm. 79, septiembre-octubre de 1985, Caracas, pp. 4-7.

${ }^{17}$ Sólo en el periodo 1985-86 asciende a 60 millones de dólares.

${ }^{18} \mathrm{La}$ Coca Cola Foods paga 6000000 de dólares por casi 80000 hectáreas cuyo precio en el mer- 
ta Gorda en 1986, de la estación de radio de Estados Unidos "La Voz de América" (VOA), que transmite programas en contra de los sandinistas y de la guerrilla salvadoreña ${ }^{19} \mathrm{y}$, finalmente, el entrenamiento de las fuerzas de defensa beliceñas en Panamá.

Así, arribamos al proceso electoral de 1989 dondese puedehablar de poco más de 82000 electores que participaron en la votación para elegir a los 28 diputados quienes, a su vez, deciden en quién recae el cargo de primer ministro. La lucha por el control del parlamento y del nuevo gobierno se reduce a dos coaliciones: el PDU (en el poder) y el PUP. A este último se adhieren la Democracia Cristiana y el Partido Popular, partidos ambos que en las elecciones de 1984 presentan candidatos propios. ${ }^{20}$

De hecho, la consulta electoral debía llevarse a cabo en diciembre, pero $\mathrm{Ma}$ nuel Esquivel decide adelantarla para aprovechar una coyuntura económica favorable. ${ }^{21}$

El programa de Esquivel se basa en la continuación del proyecto liberal, mientras que Price, al tiempo que denuncia la política económica del gobierno de Esquivel ${ }^{22}$ calificándola de conservadora y de entregar el país a los inversionistas extranjeros, propone el retorno a la eco-

cado es de 60000000 de dólares. El Día, 29 de agosto de 1989.

${ }^{19}$ El Día, ll de agosto de 1989.

${ }^{20}$ El Día, 4 de septiembre de 1989.

${ }^{21}$ Ibid.

${ }^{22}$ Price acusa a Esquivel de manipular las estadísticas y denuncia un descenso tanto en la producción local como en las exportaciones y la existencia de un gran déficit público. Además, Price señala que en los dos primeros años del gobiemo de Esquivel, éste vende casi $13 \%$ del territorio nacional (más de 300000 hectáreas) a compañias extranjeras a precios irrisorios. ElDia, 29 de agosto de 1989. nomía mixta y a una política más nacionalista.

Paralelamente, Price y Esquivel comparten la misma posición hacia Guatemala, quien mantiene su reclamo sobre el territorio beliceño y busca, por lo menos, una nueva salida al Caribe a través de Belice. ${ }^{23}$

Los resultados de las elecciones de 1989 parecen sorprendentes, ya que la mayoría de los pronósticos aseguran la victoria del PDU. Sin embargo, existe un antecedente que permite, de alguna manera, vislumbrar el resultado electoral: las elecciones municipales de abril de 1988 , en las cuales el PUP triunfa definitivamente en el interior del país. De aquí que, en las elecciones de septiembre de 1989, el PDU se proclame anticipadamente vencedor en la ciudad de Belice y sus alrededores, mientras que el pup se adjudica una amplia victoria en el resto del territorio. ${ }^{24}$

Finalmente, los resultados globales dan la victoria a Price en forma bastante apretada (quince votos a favor del pup contra trece a favor del PDU), siendo los votos rurales los que deciden la vuelta de Price al poder. ${ }^{25}$

\section{EL ESPEJISMO BIPARTIDISTA}

Como ya decíamos, durante más de tres décadas el eje de la actividad política de lus partidos es la lucha por la independencia. En consecuencia, los partidos políticos no presentan una clara diferenciación en cuanto a un proyecto de desarrollo económico, político y social para Belice ya que, en gran medida, el punto de conflicto es por mucho tiempo su

${ }^{23}$ El Día, 4 de septiembre de 1989.

${ }^{24}$ El Día, 4 y 5 de septiembre de 1989.

${ }^{25}$ El Día, 6 de septiembre de 1989.

\section{(n)}



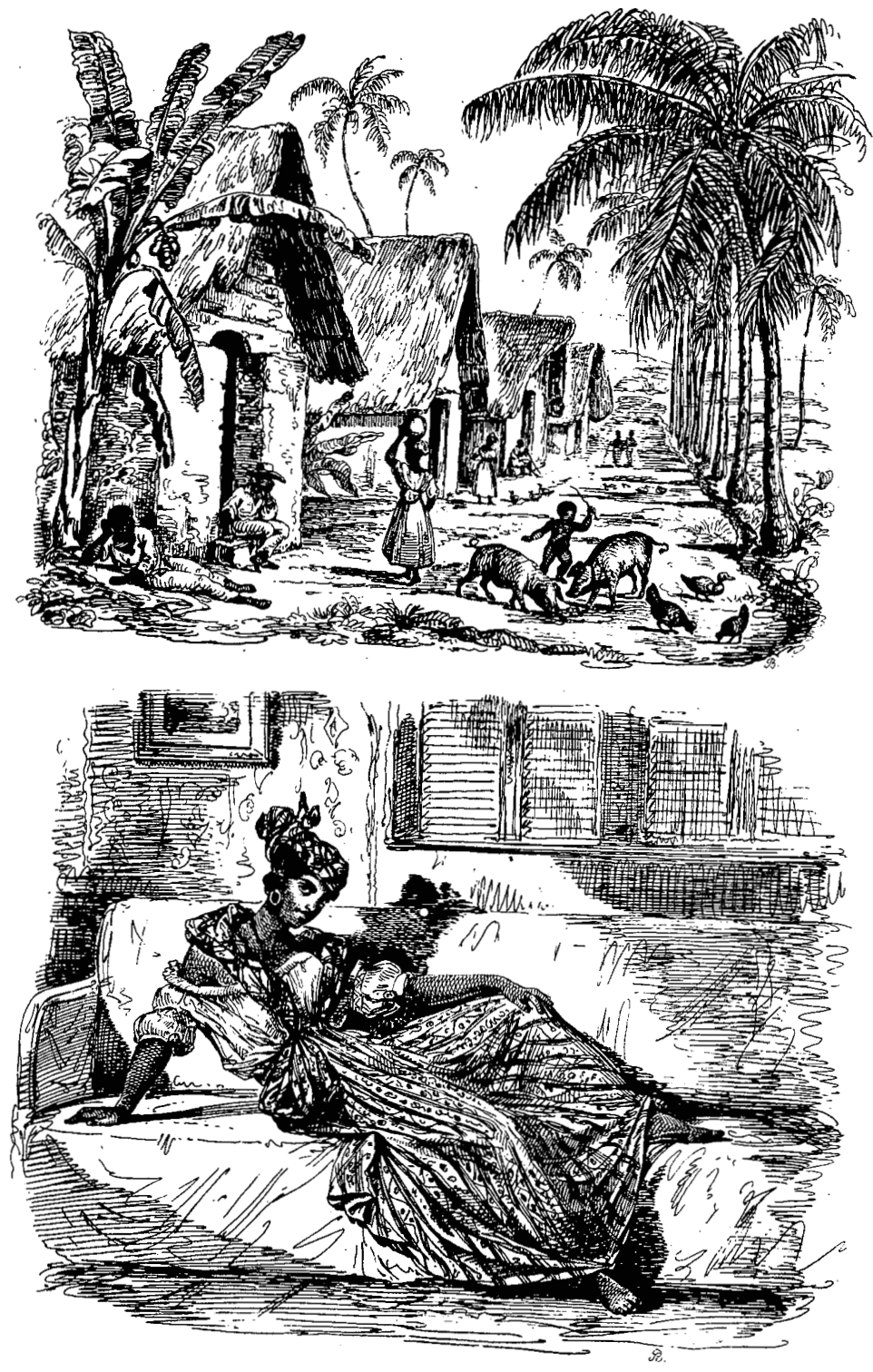
relación con Gran Bretaña. De aquí que sus planteamientos políticos no sean del todo opuestos y, lo que es más importante, que en la práctica gubernamental concreta sus políticas hayan sido relativamente semejantes.

Así, ambos partidos se declaran anticomunistas, en pro de la empresa privada y a favor de la inversión extranjera como requisito indispensable para el desarrollo económico, ${ }^{26}$ además plantean la necesidad de consolidar la economía basada en las exportaciones y se manifiestan en contra del reclamo guatemalteco. En ambos casos, de alguna manera se ha pretendido sustituir una potencia por otra, es decir, los dos partidosse han mostrado proclives a buscar la ayuda norteamericana $y$, por lo mismo, han favorecido la dependencia de Belice de Estados Unidos y de las políticas del Fondo Monetario Internacional. ${ }^{27}$

Asimismo, en cuanto a política económica, tanto el PUP como el PDU han propuesto diversificar e incrementar las exportaciones por medio de la ampliación de facilidades para la instalación de empresas extranjeras especializadas en productos agroindustriales: cítricos, azúcar, alimentos y textiles, ${ }^{28}$ lo que permi-

${ }^{26} \mathrm{~A}$ tal grado, que se ha limitado el derecho a la libre sindicalización, ya que las empresas extranjeras ponen como condición una relación laboral "libre", sin sindicatos. Esta situación se ha extendido a las empresas locales por lo que cerca de $40 \%$ de la fuerza laboral no está sindicalizada, Pablo Álvarez Icaza, op. cit. , p. 25.

27 A partir de 1984 el déficit público se ha cubierto con empréstitos lo que ha propiciado la intervención de organismos financieros internacionales como el FMI, el Banco Mundial y la AID, Pablo Alvarez Icaza, op. cit., p. 37.

${ }^{29}$ Esto se observa tanto en el "Manifiesto de la Revolución Progresiva" del pupen 1980 como en la "Plataforma Electoral del PDU" en 1984, ibid, p. 36. tiría apoyar la creación de empleos. De esta manera, más allá de la lucha por la independencia, la ideología nacionalista y anticolonialista del PUP se ha venido abajo, especialmenteen su posición frente al capital extranjero.

De lo anterior, podemos desprender tres elementos de conclusión:

1) Hasta ahora, la lucha electoral no se ha definido con base en el enfrentamiento de proyectos económicos y políticos diferenciados, sino en función de lealtades y liderazgos personales, redes de clientelismo y prácticas políticas de corte populista y paternalista.

2) La falta de una definición clara en los planteamientos de los partidos políticos ha conllevado la formación de partidos fundamentalmente electorales, sin una base social de apoyo, y pluriclasistas, que distan mucho de identificarse con los intereses de una clase, un grupo o una etnia en particular.

3) La amenaza guatemalteca a la soberanía beliceña ha sido un elemento unificador pero a la vez distractivo de las posibles diferencias políticas e ideológicas y de la elaboración de un modelo de desarrollo económico para Belice, elementos todos que los partidos políticos deben empezar a definir en un proceso de identificación y consolidación que aún está por venir.

\section{ELECCIONES Y NEOCOLONIALISMO}

Para analizar las posibilidades futuras de los partidos políticos y los procesos electorales beliceños es necesario partir de ciertas consideraciones.

Consecuencia de siglos de colonialismo, la economía de Belice se caracteriza por una gran debilidad estructural. Se trata de un país predominantemente agrícola, cuya economía se basa funda-

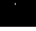




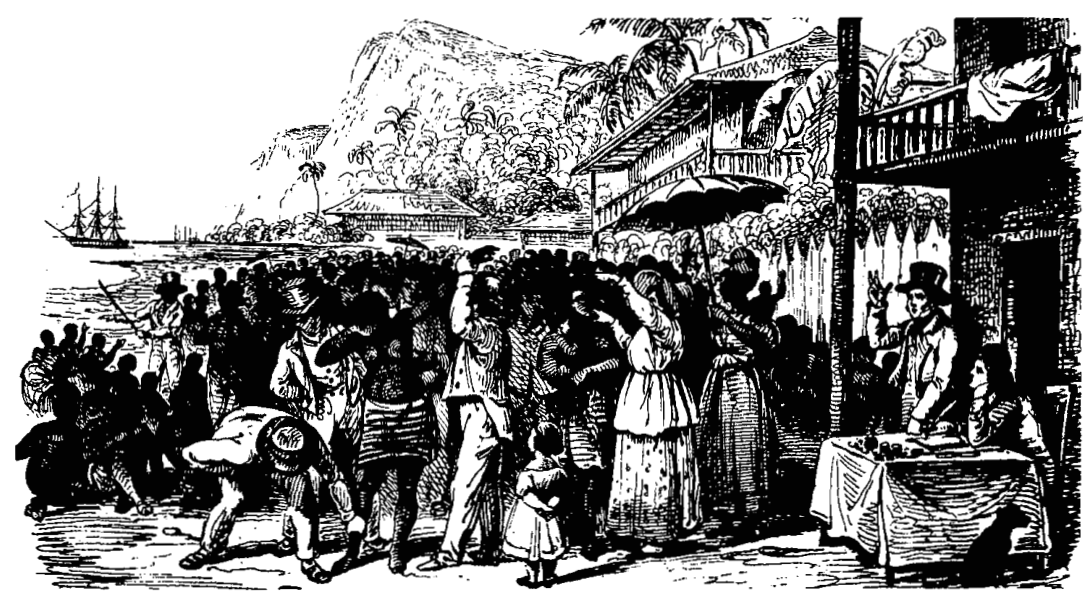

mentalmente en la exportación de azúcar y, en menor escala, de cítricos y banano. Las tasas de desempleo y subempleo se acercan a $20 \%$, a lo cual se suman el desequilibrio crónico de la balanza comercial y la dependencia comercial y financiera respecto a Inglaterra y, a partir de 1975, crecientemente en relación con Estados Unidos y Jamaica.

Aunada a la existencia de un sistema político heredado por su ex metrópoli, encontramos una sociedad atomizada étnicamente ${ }^{29} \mathrm{y}$ escindida por un corte vertical debido al bipartidismo. Además, a pesar de que la amenaza guatemalteca ha sido causa de que Belice se haya aislado del resto del istmo centroamericano, es indispensable reconocersu papel estratégico en la región, su importancia geopolítica en el marco del conflicto centroamericano. Paradójicamente, Be-

\footnotetext{
${ }^{29}$ La población está constituida por diversos grupos raciales: el negro de ascendencia africana (60\%); el resto formado por beliceños de origen maya, mestizos maya-españoles, caribes negroso garífuna (mezcla de caribes isleños y africanos), blancos de origen inglés y las mezclas subsecuentes, Carlos Quenan, op. cit, p. 77 .
}

lice es un país sin capacidad de autodefensa ${ }^{30} y$, por ende, sumamente vulnerable a la penetración económica, política, cultural e incluso militar por parte de las potencias extranjeras.

Así, pues, en Belice las elecciones no han sido determinantes ya que política y económicamente se encuentra inmerso en una situación claramente neocolonialista. En todo caso, las elecciones podrán jugar un papel significativo en la vida pública beliceña en la medida en que los partidos políticos logren formular un proyecto nacional en función de los problemas y necesidades beliceños, y ya no dependiendo de una amenaza externa.

En suma, será indispensable asumir una nueva posición frente al capital extranjero y afrontar una perspectiva en contra del neocolonialismo que ponga en práctica la consigna de Price: "Independencia hoy, liberación mañana." Definitivamente, ese mañana ya está aquí.

\footnotetext{
${ }^{30}$ Las fuerzas de defensa beliceñas cuentan con elementos británicos y alrededor de 600 beliceños.
} 